\title{
Simultaneous retrieval of effective refractive index and density from size distribution and light-scattering data: weakly absorbing aerosol
}

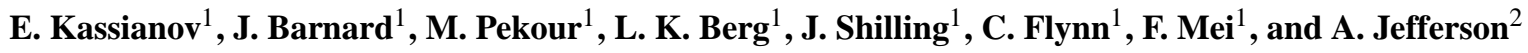 \\ ${ }^{1}$ Pacific Northwest National Laboratory, Richland, WA 99352, USA \\ ${ }^{2}$ Cooperative Institute for Research in Environmental Sciences, University of Colorado, Boulder, CO 80305, USA \\ Correspondence to: E. Kassianov (evgueni.kassianov@pnnl.gov)
}

Received: 7 April 2014 - Published in Atmos. Meas. Tech. Discuss.: 20 May 2014

Revised: 1 September 2014 - Accepted: 3 September 2014 - Published: 1 October 2014

\begin{abstract}
We propose here a novel approach for retrieving in parallel the effective density and real refractive index of weakly absorbing aerosol from optical and size distribution measurements. Here we define "weakly absorbing" as aerosol single-scattering albedos that exceed 0.95 at $0.5 \mu \mathrm{m}$. The required optical measurements are the scattering coefficient and the hemispheric backscatter fraction, obtained in this work from an integrating nephelometer. The required size spectra come from mobility and aerodynamic particle size spectrometers commonly referred to as a scanning mobility particle sizer and an aerodynamic particle sizer. The performance of this approach is first evaluated using a sensitivity study with synthetically generated but measurementrelated inputs. The sensitivity study reveals that the proposed approach is robust to random noise; additionally the uncertainties of the retrieval are almost linearly proportional to the measurement errors, and these uncertainties are smaller for the real refractive index than for the effective density. Next, actual measurements are used to evaluate our approach. These measurements include the optical, microphysical, and chemical properties of weakly absorbing aerosol which are representative of a variety of coastal summertime conditions observed during the Two-Column Aerosol Project (TCAP; http://campaign.arm.gov/tcap/). The evaluation includes calculating the root mean square error (RMSE) between the aerosol characteristics retrieved by our approach, and the same quantities calculated using the conventional volume mixing rule for chemical constituents. For dry conditions (defined in this work as relative humidity less than $55 \%$ ) and sub-micron particles, a very good (RMSE 3\%) and reasonable (RMSE $\sim 28 \%$ ) agreement is obtained for the retrieved real refractive index $(1.49 \pm 0.02)$ and effective
\end{abstract}

density $(1.68 \pm 0.21)$, respectively. Our approach permits discrimination between the retrieved aerosol characteristics of sub-micron and sub-10-micron particles. The evaluation results also reveal that the retrieved density and refractive index tend to decrease with an increase of the relative humidity.

\section{Introduction}

The density of aerosol particles $(\rho)$ is an important physical characteristic due to its strong connection to emission sources and atmospheric processes, such as transport and residence time (e.g., Cross et al., 2007). Increasing interest in the density usually concentrates on the essential linkage between volume and mass distributions. The particle refractive index $(n)$, which couples volume distributions with climate-relevant optical properties (e.g., Ghan and Schwartz, 2007), is equally important. Estimation of the particle refractive index and density from in situ measurements typically requires information on chemical composition, assumed values of the refractive index for each component, and an application of mixing rules (e.g., DeCarlo et al., 2004; Barnard et al., 2010; Matsui et al., 2013). In addition to the conventional chemically based approach, several techniques have been developed for estimating these characteristics from the lightscattering measurements (the so-called optical closure methods), and from an alignment of size spectra measured by instruments with different size ranges (the so-called alignment methods).

The optical closure methods infer the real and/or imaginary parts of the refractive index of aerosol particles from simultaneously measured optical properties and size 
distributions (e.g., Liu and Daum, 2000; Mack et al., 2010). The solution of this inverse light-scattering problem is commonly achieved through iterative schemes, where the difference between measured and calculated optical properties is minimized. The design of these schemes is driven by selection of the particular light-scattering data that are available and may include the aerosol optical properties from in situ and lidar measurements (e.g., Liu and Daum, 2000; Raut and Chazette, 2007; Wex et al., 2002). A common feature of the optical closure studies is the use of combined particle size distributions with a wide size range and an assumed effective density, which is required for obtaining these combined distributions (Table 1). However, because the sensitivity of the solution to the effective density is large and its assumed value may differ substantially from reality, it is highly desirable to solve the inverse light-scattering problem using density values obtained from other methods, such as alignment methods.

Alignment methods are designed to estimate the effective density from size distributions measured simultaneously by different aerosol sizing instruments (e.g., Hand and Kreidenweis, 2002; Khlystov et al., 2004). The solution is achieved by merging two measured size distributions with different size ranges into a single combined spectrum with a wider size range. During this merging process, the measured spectra are compared in the instruments' size overlap region. The best-fit solution is determined by finding the minimum of a merit function, which is often proportional to the squared difference between the two measured size distributions in the overlap region. The design of these schemes is driven by selection of the spectrum type and may include data consisting of both mobility and aerodynamic sizes (Khlystov et al., 2004). For spherical singly charged particles, the mobility diameter is equal to the geometric diameter $\left(D_{\mathrm{p}}\right)$, while the aerodynamic diameter $\left(D_{\mathrm{a}}\right)$ is linked to the geometric diameter $\left(D_{\mathrm{p}}\right)$ through the well-known relationship $D_{\mathrm{p}}=D_{\mathrm{a}} / \sqrt{\rho}$ (e.g., Baron and Willeke, 2001, p. 51). The aerodynamic particle diameter corrected by density represents volumeequivalent particle diameter (DeCarlo et al., 2004). The distinguishing feature of the alignment methods is the use of the effective density to convert the aerodynamic diameter into the geometric diameter. Note that measurements of the mobility and aerodynamic particle number size distributions in tandem with the optical size spectra enable simultaneous retrieval of the effective density and real refractive index of weakly absorbing aerosol (Hand and Kreidenweis, 2002). The term "weakly absorbing" will be used throughout our paper to describe situations when values of aerosol singlescattering albedo are large ( $>0.95)$. These values are typical for marine aerosol (e.g., Fujitani et al., 2007; Kassianov et al., 2013; Berg et al., 2014).

In this work we put forth a novel technique for inferring in parallel the effective density and real refractive index of weakly absorbing aerosols from simultaneously measured size distributions (with mobility and aerodynamic particle diameters), and two measured optical properties, namely the particle light-scattering coefficient $\left(\sigma_{\mathrm{s}}\right)$ and hemispheric backscatter fraction $(\beta)$. The backscatter fraction is defined as the ratio of the hemispheric backscattering and total scattering coefficients. The choice of these two widely measured optical properties is motivated by their different sensitivities to the effective density, as explained in Sect. 2 below. The inclusion of these two optical constraints $\left(\sigma_{\mathrm{s}}\right.$ and $\beta$ ) coupled with measured size distributions enables estimation of the effective density and real refractive index simultaneously. Moreover, it is well known that the aerosol optical depth $\left(\tau_{\mathrm{a}}\right)$, asymmetry factor $(g)$, and single-scattering albedo are the most important aerosol optical parameters for numerous climate-relevant applications, including the Earth's radiation budget (e.g., McComiskey et al., 2008). The role of singlescattering albedo is more pronounced for highly absorbing aerosols (e.g., Bond et al., 2009, and references therein). It is widely recognized that $\tau_{\mathrm{a}}$ and $g$ are strongly related to the scattering coefficient and hemispheric backscatter fraction, respectively (e.g., Andrews et al., 2006). Therefore, the estimation of $n$ and $\rho$ can be extended to the calculation of these two climate-relevant aerosol optical properties. Finally, our technique allows for determining the difference between the retrieved aerosol characteristics of sub-micron $\left(D_{\mathrm{p}}<1 \mu \mathrm{m}\right)$ and sub-10-micron $\left(D_{\mathrm{p}}<10 \mu \mathrm{m}\right)$ particles. Given that there is a dearth of routinely deployed instruments that provide information on large $\left(1 \mu \mathrm{m}<D_{\mathrm{p}}<10 \mu \mathrm{m}\right)$ particles, our technique gives an opportunity for obtaining this important information from widely used observations.

In Sect. 2 we provide details of our method. In Sect. 3 we evaluate the performance of our approach through a sensitivity study utilizing simulated but measurement-based inputs. In Sect. 4, we describe an integrated data set for its evaluation. This data set includes the optical, microphysical, and chemical properties of weakly absorbing aerosol collected during the Two-Column Aerosol Project (TCAP; Berg et al., 2014), which was conducted with support from the US Department of Energy's (DOE's) Atmospheric Radiation Measurement (ARM) program (http://www.arm.gov/). Also, we compare aerosol characteristics retrieved by our method with those obtained from the conventional volume mixing rule applied to chemical composition measurements. We summarize the evaluation results in the last section.

\section{Approach}

As mentioned previously, our retrieval approach utilizes two complementary and simultaneously obtained data sets. The first data set includes two observational quantities: the total scattering coefficient $\left(\sigma_{\mathrm{s}, \mathrm{obs}}\right)$ and hemispheric backscatter fraction $\left(\beta_{\text {obs }}\right)$ measured by a TSI 3563 Integrating Nephelometer. Throughout this work we use the subscript "obs" to indicate observed quantities. Although the nephelometer provides the light-scattering measurements at three wavelengths 
Table 1. Examples of the typical light-scattering data, measured particle number size distributions, and assumed values of particle density used for the optical closure studies under marine conditions. The listed examples illustrate a variety of instruments for measuring the lightscattering properties and size spectra, as well as a wide range of assumed values of particle density (from 1 to $2.2 \mathrm{~g} \mathrm{~cm}^{-3}$ ).

\begin{tabular}{lccll}
\hline $\begin{array}{l}\text { Light-scattering } \\
\text { observations }\end{array}$ & $\begin{array}{c}\text { Size distribution } \\
\text { measurements }\end{array}$ & $\begin{array}{c}\text { Assumed } \\
\text { density }\end{array}$ & $\begin{array}{l}\text { Environmental } \\
\text { conditions }\end{array}$ & Reference \\
\hline $\begin{array}{l}\text { Integrating } \\
\text { neplelometer 3563 }\end{array}$ & $\begin{array}{c}\text { SMPS 3936 } \\
\text { APS } 3321^{\mathrm{c}}\end{array}$ & $2.2 \mathrm{~g} \mathrm{~cm}^{-3}$ & $\begin{array}{l}\text { Mixture of marine aerosol } \\
\text { with small fraction } \\
\text { of absorbing particles }\end{array}$ & Guerrero-Rascado et al. (2011) \\
$\begin{array}{l}\text { Raman lidar Sun } \\
\text { photometer Cimel }\end{array}$ & PCASP-100X & & Marine aerosol & Chamaillard et al. (2006) \\
\hline $\begin{array}{l}\text { Integrating } \\
\text { neplelometer } 3563^{\mathrm{a}}\end{array}$ & $\begin{array}{c}\text { ELPI } \\
\text { APS 3320 }\end{array}$ & $1.0 \mathrm{~g} \mathrm{~cm}^{-3}$ & M & \\
\hline
\end{tabular}

a TSI Integrating Nephelometer 3563 measures the total and hemispheric backscatter light-scattering coefficients at three wavelengths $(0.45$, 0.55 , and $0.70 \mu \mathrm{m})(\mathrm{http}: / /$ www.tsi.com/Integrating-Nephelometer-3563/).

b TSI Scanning Mobility Particle Sizer (SMPS) 3936 measures aerosols with 0.003-1.0 $\mu$ m electrical mobility size range (http://www.tsi.com/scanning-mobility-particle-sizer-spectrometer-3936/).

c TSI Aerodynamic Particle Sizer (APS) 3321 measures aerosols with 0.5-20.0 $\mu \mathrm{m}$ aerodynamic size range

(http://www.tsi.com/aerodynamic-particle-sizer-spectrometer-3321/).

d Passive Cavity Aerosol Spectrometer (PCASP)-100X measures aerosols with 0.1-3.0 $\mu \mathrm{m}$ optical equivalent radius range

(http://www.dropletmeasurement.com/products/airborne/PCASP-100X).

e Electrical low-pressure impactor (ELPI) measures aerosols with $0.007-10.0 \mu \mathrm{m}$ aerodynamic size range

(http://www.environmental-expert.com/products/elpi-electrical-low-pressure-impactor-172157).

$(0.45,0.55$, and $0.70 \mu \mathrm{m})$, here we only consider aerosol optical properties at a wavelength of $0.55 \mu \mathrm{m}$. The spectral dependence of the retrieved real refractive index will be the subject of our future studies. The second data set includes observed particle number size distributions measured by a mobility particle size spectrometer commonly referred to as TSI Scanning Mobility Particle Sizer (SMPS) with a 0.01$0.48 \mu \mathrm{m}$ electrical mobility diameter range, and an aerodynamic particle size spectrometer commonly referred to as TSI 3321 Aerodynamic Particle Sizer (APS) with a $0.52-$ $19.8 \mu \mathrm{m}$ aerodynamic diameter range. Note that Wiedensohler et al. (2012) carefully considered important issues related to high-quality measurements of particle number size distributions and provided recommendations on technical and data structure standards. TCAP data from these instruments are discussed in Sect. 4.

The general concept behind the simultaneous retrieval of $n$ and $\rho$ is enumerated as follows:

1. Shifting the APS number distribution to form a combined size distribution. By changing the effective density, the APS number distribution is shifted horizontally along the abscissa $D_{\mathrm{p}}$ - a procedure similar to the alignment method (Fig. 1a). The SMPS spectrum remains unchanged. Such shifting of APS number distribution modifies the relative contribution of particles with moderate (about $0.5-1.0 \mu \mathrm{m})$ and large $(>1 \mu \mathrm{m})$ diameters to the light scattering. These relative contributions as a function of $D_{\mathrm{p}}$ control the total scattering coefficient $\left(\sigma_{\mathrm{s}}\right)$ and hemispheric backscatter fraction $(\beta)$ quite differently. For example, a reduction in the number of particles with moderate diameter, which scatter sunlight most efficiently, results mainly in a decrease of the total scattering coefficient $\left(\sigma_{\mathrm{s}}\right)$. In contrast, a reduction in the number of particles with large diameter, which are generally responsible for the forward scattering of sunlight, results mostly in an increase of hemispheric backscatter fraction $\beta$. These distinct dependences of $\sigma_{\mathrm{s}}$ and $\beta$ form the basis of our retrieval. We obtain combined SMPSAPS distributions for a set of assumed $\rho$ values within a wide range $(1.0 \leq \rho \leq 2.6)$, which represents reasonable values of $\rho$ appearing in the literature (e.g., Barnard et al., 2010).

2. Calculate modeled optical properties from combined size distribution. Next we apply a technique similar to the optical closure methods (e.g., Liu and Daum, 2000; Mack et al., 2010) by using the particle number size distributions found in step (1) above, and Mie theory, to calculate modeled optical properties $\sigma_{\mathrm{s}, \bmod }$ and $\beta_{\text {mod }}$ (Fig. 1b, c); here the subscript "mod" refers to calculated, modeled quantities. These properties are found for an assumed imaginary refractive index (0.001) and the range of $\rho$ values mentioned above and for a set of assumed $n$. For $n$, we specify a range in values $(1.3 \leq$ $n \leq 1.7)$ that is representative of atmospheric aerosol (e.g., Barnard et al., 2010). The calculated optical properties can be considered as two-dimensional (2-D) functions of the two independent variables considered here ( $n$ and $\rho$ ) (Fig. 1b, c). The $\sigma_{\mathrm{s} \text {, mod }}$ isolines increase as the effective density increases (Fig. 1b). The opposite is true for $\beta_{\text {mod }}$ isolines (Fig. 1c). The observed opposite trends of $\sigma_{\mathrm{s}, \text { mod }}$ isolines and $\beta_{\text {mod }}$ isolines (increase versus decrease) suggest that a unique solution for $n$ and $\rho$ can be obtained. For example, isolines in Fig. $1 \mathrm{~b}$ and $\mathrm{c}$ correspond to constant values of $\sigma_{\mathrm{s}, \bmod }$ and $\beta_{\text {mod }}$. At 
a given time, observed values of these variables can be associated with a single isoline in each figure. By superimposing these two isolines over one another, and finding their intersection, $n$ and $\rho$ are determined. However, the issue of "ripple" in Fig. 1c must be addressed to find a unique solution.

3. Finding a unique solution using observed optical properties. Once observed values of the optical properties are fed to the algorithm, the process of finding a unique solution for $n$ and $\rho$ needs to address distinctive features of these 2-D diagrams: "smooth" (Fig. 1b) versus "rippled" (Fig. 1c) structures for $\sigma_{\mathrm{s} \text {, mod }}$ and $\beta_{\text {mod }}$, respectively. These features are attributable to the different responses of $\sigma_{\mathrm{s} \text {, mod }}$ and $\beta_{\text {mod }}$ to the relative contributions of moderate and large particles. Unlike $\beta_{\bmod }, \sigma_{\mathrm{s}, \bmod }$ is obtained via integration of the scattered sunlight over all angles, and this full angular integration washes out any ripple structure. The apparent difference between smooth and rippled structure is consistent with results from previous studies (e.g., Chamaillard et al., 2006; Chartier and Greenslade, 2012), which have examined differences between the backscattering and total scattering efficiencies as a function of particle diameter.

We emphasize that finding a unique solution for a domain with a rippled structure is often problematic because, in our case, the isolines can intersect in more than one place. To circumnavigate this possible problem, we select two unique populations of points from these 2-D diagrams. The first of these defines points where the observed and modeled values of the scattering coefficient agree within a given threshold (e.g., 3\%). The second population represents similar points for the backscatter fraction. These two populations of points are approximated by the corresponding polynomial fits (curves) and the solution for $n$ and $\rho$ is found by locating the intersection of these fits. Illustrative examples of such fits and the determination of the unique solution are given in the next section.

\section{Sensitivity study}

To illustrate the performance of our method, we devise a sensitivity study using the SMPS-APS particle number size distributions. In particular, results shown in Figs. 2 and 3 represent the SMPS-APS particle number size distributions measured during a selected day (17 July). We treat assumed aerosol characteristics, $n_{\text {mod }}$ and $\rho_{\text {mod }}$, as reference values. These assumed characteristics are used to calculate aerosol optical properties, $\sigma_{\mathrm{s}, \bmod }^{\varepsilon}$ and $\beta_{\text {mod }}^{\varepsilon}$. Artificial errors - devised to mimic measurement uncertainties - are added to the optical properties, and these properties along with the added errors are treated as "observations", which serve as input for our retrieval. Here and below we use the superscript " $\varepsilon$ " to indicate that errors have been added. We then retrieve aerosol
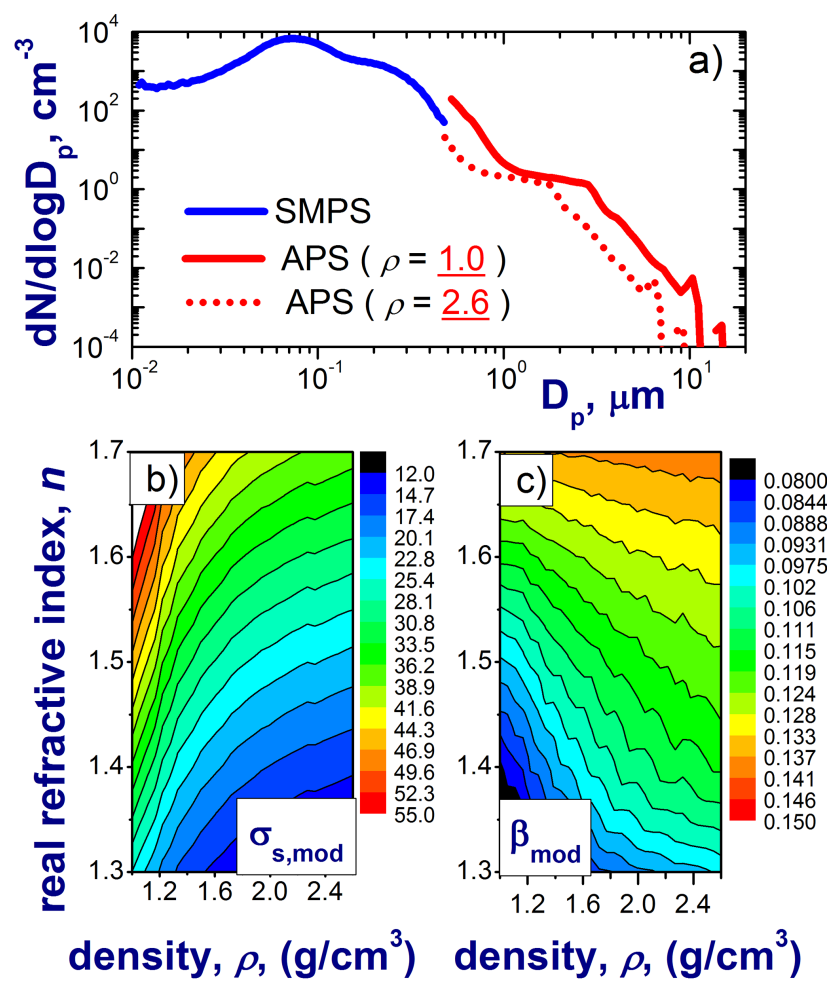

Figure 1. (a) Schematic illustration of merging the SMPS (diameter range 0.01 to $0.48 \mu \mathrm{m}$ ) and APS (diameter range 0.52 to $19.8 \mu \mathrm{m}$ ) distributions. (b, c) Example of 2-D diagrams of modeled particle light-scattering coefficient $\left(\sigma_{\mathrm{s}, \bmod }\right)(\mathbf{b})$ and hemispheric backscatter fraction $\left(\beta_{\text {mod }}\right)(\mathbf{c})$ as a function of the real refractive index $(n)$ and effective density $(\rho)$. The combined SMPS-APS distributions for a given $\rho$ are used to obtain modeled optical properties as a function of $n$.

characteristics from these "observed" optical properties. Finally, we compare the "retrieved" characteristics $\left(n_{\text {mod }}^{\varepsilon}\right.$ and $\left.\rho_{\text {mod }}^{\varepsilon}\right)$ with their reference values ( $n_{\text {mod }}$ and $\left.\rho_{\text {mod }}\right)$.

\subsection{Simulation of input data}

Although microphysical and chemical properties of aerosol do not exhibit systematic diurnal changes (Sect. 4), we assume that temporal changes of the reference values $\left(n_{\bmod }\right.$ and $\rho_{\text {mod }}$ ) can be approximated by simple functions with sine terms:

$$
\begin{aligned}
& \rho_{\text {mod }}=\rho_{0}(1 \pm \sin (t)) \\
& n_{\text {mod }}=n_{0}(1 \pm \sin (t)) .
\end{aligned}
$$

The focus of these simulations is to reproduce large temporal changes of observed aerosol optical properties (Sect. 4) using a simple representation. A sinusoidal representation with properly selected amplitudes is one of several potential ways to capture the observed variability. The amplitudes $\rho_{0}$ and $n_{0}$ are selected in such way that the span of modeled optical properties (Fig. 2a, b) matches roughly the wide range of optical properties observed during the TCAP study. Note that 

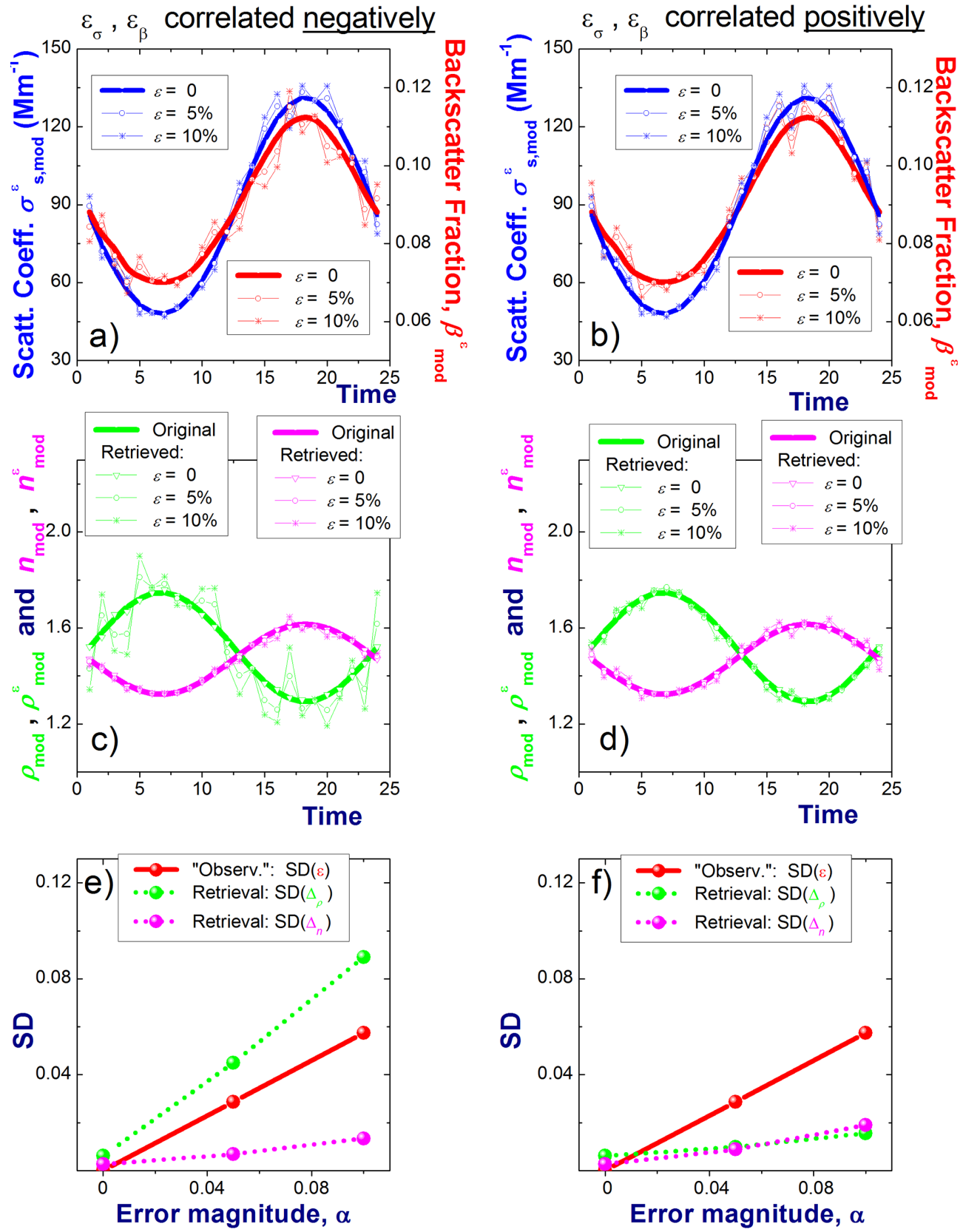

Figure 2. Example of (a, b) modeled aerosol optical properties (scattering coefficient $\sigma_{\mathrm{s} \text {,mod }}^{\varepsilon}$ and backscatter fraction $\beta_{\text {mod }}^{\varepsilon}$ ) with different magnitudes $(0,5$, and $10 \%)$ of the added errors $\left(\varepsilon_{\sigma}\right.$ and $\left.\varepsilon_{\beta}\right) ;(\mathbf{c}, \mathbf{d})$ the corresponding "retrieved" aerosol characteristics $($ effective density $\rho_{\text {mod }}^{\varepsilon}$ and real refractive index $n_{\text {mod }}^{\varepsilon}$ ) and their original counterparts ( $\rho_{\text {mod }}$ and $n_{\text {mod }}$ ); and (e, f) the standard deviation (SD) of differences between the original and retrieved aerosol characteristics $\left(\Delta_{\rho}\right.$ and $\left.\Delta_{n}\right)$ and the SD of the "observational" errors for two extreme cases: the observational errors $\left(\varepsilon_{\sigma}\right.$ and $\left.\varepsilon_{\beta}\right)$ are correlated negatively (left column) and positively (right column). See text for details.

in our sensitivity study we generate observations for a $24 \mathrm{~h}$ period.

To estimate the sensitivity of our method to measurement uncertainties, we add "observational" errors $\left(\varepsilon_{\sigma}\right.$ and $\left.\varepsilon_{\beta}\right)$ to the corresponding "error-free" modeled optical properties:

$$
\begin{aligned}
& \sigma_{\mathrm{s}, \text { mod }}^{\varepsilon}=\sigma_{\mathrm{s}, \bmod }\left(1 \pm \varepsilon_{\sigma}\right) \\
& \beta_{\text {mod }}^{\varepsilon}=\beta_{\text {mod }}\left(1 \pm \varepsilon_{\beta}\right) .
\end{aligned}
$$

These errors are related to the uncertainties in the lightscattering measurements and are defined for two extreme cases. The first case represents a situation where the errors have the same magnitudes and signs (positively correlated errors): $\sigma_{\mathrm{s}, \text { mod }}^{\varepsilon}=\sigma_{\mathrm{s} \text {, mod }}(1+\varepsilon), \beta_{\mathrm{mod}}^{\varepsilon}=\beta_{\mathrm{mod}}(1+\varepsilon)$. The second case describes situation when these errors have the same magnitudes but different signs (negatively correlated errors): 
$\sigma_{\mathrm{s}, \bmod }^{\varepsilon}=\sigma_{\mathrm{s}, \bmod }(1+\varepsilon), \beta_{\mathrm{mod}}^{\varepsilon}=\beta_{\mathrm{mod}}(1-\varepsilon)$. The assumed error $\varepsilon$ is distributed uniformly over the interval $(\alpha,-\alpha)$, where $\alpha$ is the relative magnitude $(0,5$, or $10 \%)$, defined as a percentage of the error-free optical properties. Note that the uncertainties in the light-scattering measurements are about $\pm 10 \%$ (e.g., Anderson et al., 1996).

Figure 2 (top panel) shows examples of simulated optical properties $\left(\sigma_{\mathrm{s}, \text { mod }}^{\varepsilon}\right.$ and $\left.\beta_{\text {mod }}^{\varepsilon}\right)$ for two extreme cases with different magnitudes of the observational errors, while Fig. 2 (middle panel) and Fig. 3 illustrate the sensitivity of the solution to these errors. There are small differences between the aerosol characteristics retrieved for the error-free and "noisy" conditions with positively correlated errors (Figs. 2d and $3 \mathrm{a}, \mathrm{b}$ ). This encouraging result indicates clearly that the obtained solution $\left(n_{\text {mod }}^{\varepsilon}\right.$ and $\left.\rho_{\text {mod }}^{\varepsilon}\right)$ depends weakly on the positively correlated observational errors $\left(\varepsilon_{\sigma}\right.$ and $\left.\varepsilon_{\beta}\right)$. This sensitivity becomes relatively stronger for the noisy conditions with negatively correlated errors (Figs. 2c and 3a, c). However, the error-induced differences between the retrieved aerosol characteristics for the error-free and noisy conditions do not exceed 10 and $35 \%$ for the real refractive index and density, respectively (Fig. 3a, c). Note that illustration considered here represents an "unfavorable" case with large error-induced differences. On average, these differences are smaller (Fig. 2c, d).

\subsection{Comparison of retrieved and original aerosol characteristics}

To assess this sensitivity quantitatively, we calculate differences between the retrieved and original characteristics for each $1 \mathrm{~h}$ time step within the $24 \mathrm{~h}$ diurnal cycle:

$$
\begin{aligned}
& \Delta_{\rho}=\rho_{\text {mod }}-\rho_{\text {mod }}^{\varepsilon} \\
& \Delta_{n}=n_{\text {mod }}-n_{\text {mod }}^{\varepsilon} .
\end{aligned}
$$

We calculate standard deviations of the above difference for different values of $\alpha$ for the same $24 \mathrm{~h}$ period, and in Fig. 2 (bottom panel) we display the statistics $\operatorname{SD}\left(\Delta_{\rho}\right)$, $\operatorname{SD}\left(\Delta_{n}\right)$, and $\operatorname{SD}(\varepsilon)$ as a function of the magnitude of $\alpha$.

On average, these differences $\left(\Delta_{\rho}\right.$ and $\left.\Delta_{n}\right)$ should be zero for error-free conditions $(\alpha=0)$. The averaged difference found under error-free conditions is close to zero (Fig. 2e, f). The small deviation $(<0.01)$ of this difference from zero suggests that our simple retrieval reproduces the "original" characteristics reasonably well under favorable error-free conditions. Under unfavorable noisy conditions, differences of the retrieved aerosol characteristics, $\Delta_{\rho}$ and $\Delta_{n}$, and the standard deviations of these differences increase almost linearly with the magnitude of the errors. This increase is more pronounced for the negatively correlated errors than for the positively correlated errors (Fig. 2: left column versus right column). In comparison with $\Delta_{n}, \Delta_{\rho}$ is more sensitive to errors (Fig. 2). Such sensitivity is governed mostly by different impacts of these aerosol characteristics on the aerosol optical properties. Overall, the results of the sensitivity study
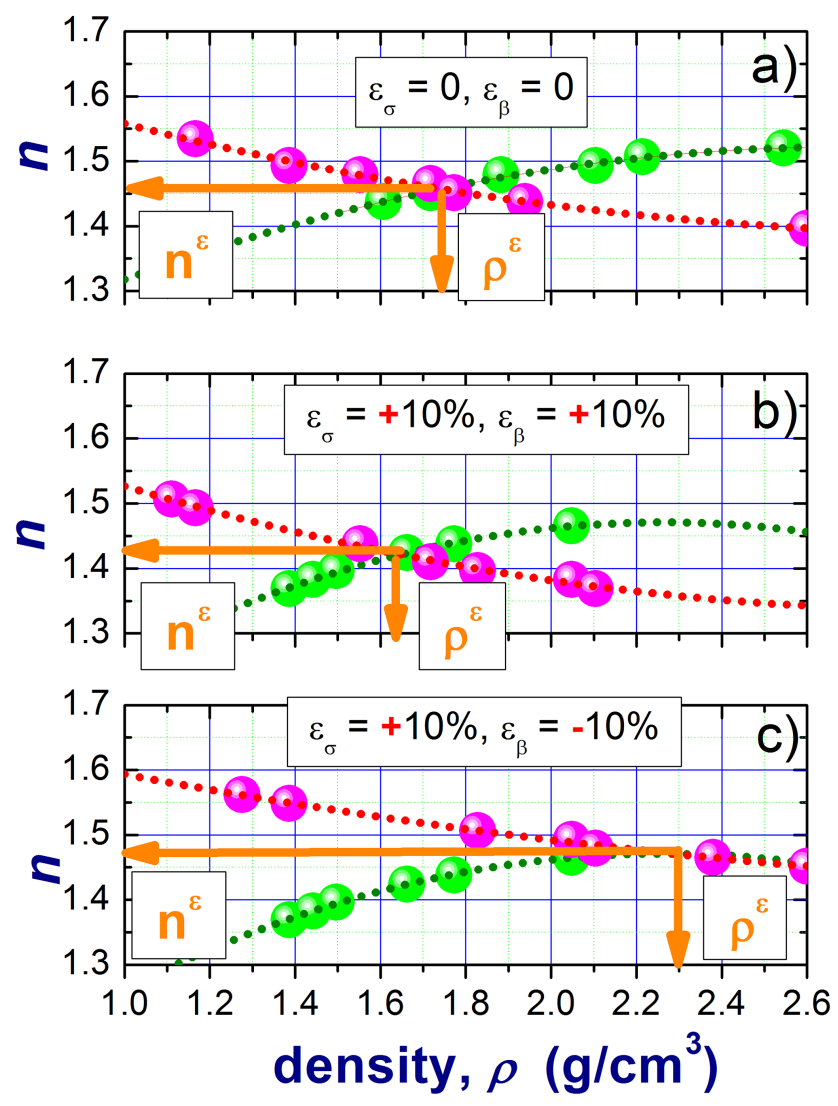

Figure 3. Schematic illustration of retrieving aerosol characteristics for three cases: (a) "error-free" conditions when the observational errors $\left(\varepsilon_{\sigma}\right.$ and $\left.\varepsilon_{\beta}\right)$ are zero, $(\mathbf{b}, \mathbf{c})$ "noisy" conditions when the observational errors are positively (b) or negatively (c) correlated. The family of green points is an isoline of the assumed scattering coefficient at a given time, and, in a similar vein, the magenta points represent an isoline of the assumed backscatter fraction. The corresponding polynomial fits (dotted lines with blue and red colors) are used for obtaining the solution $\left(n_{\bmod }^{\varepsilon}\right.$ and $\left.\rho_{\text {mod }}^{\varepsilon}\right)$. This illustration represents the error-free and noisy conditions from Fig. $2 \mathrm{c}$ and $\mathrm{d}$ for a given instant (Time $=2$ ). Note that the crossing isolines are related to the 2-D diagrams of $\sigma_{\mathrm{s}, \bmod }$ and $\beta_{\bmod }$ (e.g., Fig. 1b, c) calculated for assumed $n$ and $\rho$.

demonstrate that (1) our retrieval has the benefit of being robust to random noise, (2) the uncertainties of the aerosol retrieval are almost linearly proportional to the measurement errors, and (3) these uncertainties are smaller for the retrieved real refractive index compared to the retrieved effective density.

\section{Case study}

Thus far, we have discussed the application of our retrieval to realistic but artificial inputs. Here, we consider its application to actual TCAP measurements. The TCAP program was designed to study the evolution of optical, microphysical, 
and chemical properties of both marine aerosol and aerosol transported from continental North America over the Atlantic Ocean and their impact on the radiation energy budget. During this project the ground-based ARM Mobile Facility (AMF) was deployed at the Highlands Center in the Cape Cod National Seashore, which is located on the easternmost portion of Massachusetts, along the east coast of the United States.

The TCAP data represent coastal summertime observations, and therefore values of ambient relative humidity $(\mathrm{RH})$ for the sample period can be quite high (70-85\%). The temporal changes of $\mathrm{RH}$ inside the nephelometer are uncontrolled due to instrumental setup, and the average $\mathrm{RH}$ value within the nephelometer is about $60 \%$. Below, the term "RH" refers to the RH inside the nephelometer. To account for the RH changes (at least partially) and their impact on optical properties and particle diameter, the lightscattering measurements and ASP data are adjusted to reference "dry" conditions $(\mathrm{RH}=40 \%)$ using standard corrections (Appendix A). In particular, we apply these corrections to the optical properties measured for sub-micron $\left(D_{\mathrm{p}}<1 \mu \mathrm{m}\right)$ and sub-10-micron $\left(D_{\mathrm{p}}<10 \mu \mathrm{m}\right)$ particles.

The AMF site $\left(41.87^{\circ} \mathrm{N} ; 70.28^{\circ} \mathrm{W}\right)$ was equipped with numerous instruments for sampling aerosol, cloud and radiative properties; a comprehensive overview of the full instrumentation is given by Berg et al. (2014). Here we consider only the measurements that are relevant in applying and evaluating our method (Figs. 4, 5 and 6a). For example, TCAP aerosol chemical composition measurements, obtained from an Aerodyne Aerosol Chemical Speciation Monitor (ACSM) and a Single Particle Soot Photometer (SP2), are shown Fig. 4. The large contribution of the organic aerosol to the total mass suggests that aerosol considered here is weakly absorbing at mid-visible wavelengths and larger (Barnard et al, 2008). High values of the single-scattering albedo (>0.95) obtained from the ground-based retrievals (Kassianov et al., 2013), in situ aircraft (e.g., Berg et al., 2014), and nearsurface (Titos et al., 2014) measurements confirm this conjecture. Similar high values of the single-scattering albedo for typical marine conditions have been reported previously (Fujitani et al., 2007, and references therein).

The retrieval is then evaluated using independently obtained values of density and refractive index obtained from measured chemical constituents (Fig. 4) and volume averaging, as described in Barnard et al. (2010). When using this method there are several factors that must be considered, which we briefly mention here. First, this method assumes that the particle number size distributions for each chemical constituent are identical. Second, the inferred density and refractive index are necessarily found from measured chemical species, and to the extent that we cannot measure all species - such as crustal materials - some error will occur. This error is expected to be small because a coarse mode is not prominently seen at the TCAP site. Finally, because the chemical measurements do not include water uptake, and
TCAP chemistry data 2012

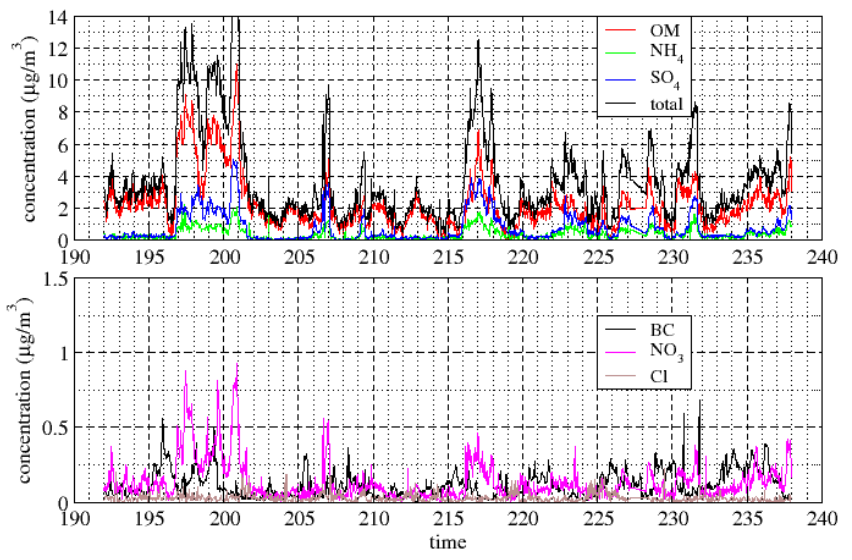

Figure 4. Time series of aerosol chemical components measured during the TCAP field experiment during summertime 2012. Here and in Figs. 5 and 6 time represents Julian day in 2012 (1 January $=1$ ). Days 190 and 214 correspond to 8 July 2012 and 1 August 2012, respectively. Organic matter $(\mathrm{OM})$, ammonium $\left(\mathrm{NH}_{4}\right)$, sulfate $\left(\mathrm{SO}_{4}\right)$, nitrate $\left(\mathrm{NO}_{3}\right)$, chloride $(\mathrm{Cl})$, and total aerosol concentrations are from ASCM measurements. Black carbon (BC) concentrations are from SP2 measurements. The BC, OM, and ionic species are used to find the effective density and refractive index using the "chemical" method. Note the large mass fraction of organic matter (OM), indicating that the aerosol is weakly absorbing at mid-visible wavelengths.

because these measurements are for sub-micron aerosol, we can only use the chemical method to find aerosol properties for these dry conditions. The values found in this manner are assigned the symbols $n_{\text {mod,chem }}$ and $\rho_{\text {mod,chem }}$. The values inferred from the measured optical properties are assigned the symbols $n_{\text {mod,opt }}$ and $\rho_{\text {mod,opt }}$; note the added subscripts "chem" and "opt". To estimate uncertainties of the retrieved aerosol characteristics, we introduce the root mean squared error (RMSE), which is defined as the root mean squared difference $(\%)$ between the aerosol characteristics retrieved from the measured optical properties and their counterparts calculated from the chemical composition data. Before considering these uncertainties, we review features of the TCAP measurements relevant for retrieving the aerosol characteristics ( $n$ and $\rho$ ) and their temporal variability.

\subsection{Temporal changes of observed and retrieved aerosol properties}

There are strong temporal changes of the observed RHcorrected sub-10-micron scattering coefficient and hemispheric backscatter fraction (Fig. 6a). However, they do not follow, in general, the observed RH variations (Fig. 6b). This confirms that the RH-corrected optical properties depend weakly on the RH variability and that the standard RH corrections (Appendix A) work reasonably well when 


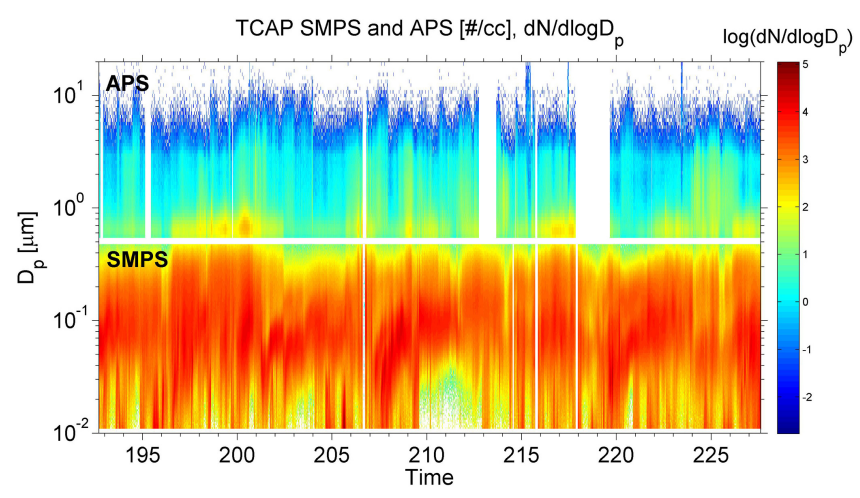

Figure 5. Time series of particle number distributions as a function of geometric diameter ( $y$ axis) measured by in situ ground-based instruments: SMPS (bottom panel) and APS (top panel). The measured SMPS and APS particle number size distributions together with optical measurements are used for retrieving the aerosol characteristics (Fig. 6c, d).

applied to the challenging observational conditions considered here. Similar to the sub-10-micron aerosol optical properties (Fig. 6a), the ratio ( $f_{\text {obs }}$ ) of sub-micron and sub-10micron scattering coefficients (Fig. 6b) also depends weakly on the RH changes. This ratio, called the fine-mode fraction of light scattering, defines the relative contribution of the sub-micron particles to the measured sub-10-micron scattering coefficient (which includes the sub-micron scattering) and is commonly used as a proxy of the aerosol source (anthropogenic versus natural). The frequently observed large values of $f_{\text {obs }}$ (Fig. 6b) suggest that the light scattering is often dominated by sub-micron particles. However, there are several events where values of $f_{\mathrm{obs}}$ are quite small (less than 0.5) (Fig. 6b). For these events, the relative contribution of large $\left(1 \mu \mathrm{m}<D_{\mathrm{p}}<10 \mu \mathrm{m}\right)$ particles to the light scattering is substantial.

The aerosol characteristics $n_{\text {mod,opt }}$ and $\rho_{\text {mod,opt }}$ retrieved from the measured optical properties $\sigma_{\mathrm{s} \text {,obs }}$ and $\beta_{\mathrm{obs}}$ show strong temporal variability (Fig. 6c, d). Occasional prolonged gaps in time series of the retrieved aerosol characteristics (Fig. 6c, d) are periods when no solution can be found. These periods typically represent optically thin conditions when values of the observed scattering coefficient are relatively small (e.g., $\sigma_{\mathrm{s}, \text { obs }}<10 \mathrm{Mm}^{-1}$ ) (Fig. 6a), and are characterized by larger values of the measurement uncertainties when compared to other periods. Also, occasional prolonged gaps occur for events where the relative contribution of large particles to the light scattering is substantial (Fig. 6b). Commonly, these large particles may have an irregular (non-spherical) geometry, which is not taken into account by the current version of our retrieval. The observed temporal variations of the retrieved aerosol properties could be attributed partially to the "weakly absorbing aerosol" assumption, especially when a noticeable amount of absorbing aerosol is present. An expected generalization of our retrieval to such absorbing cases
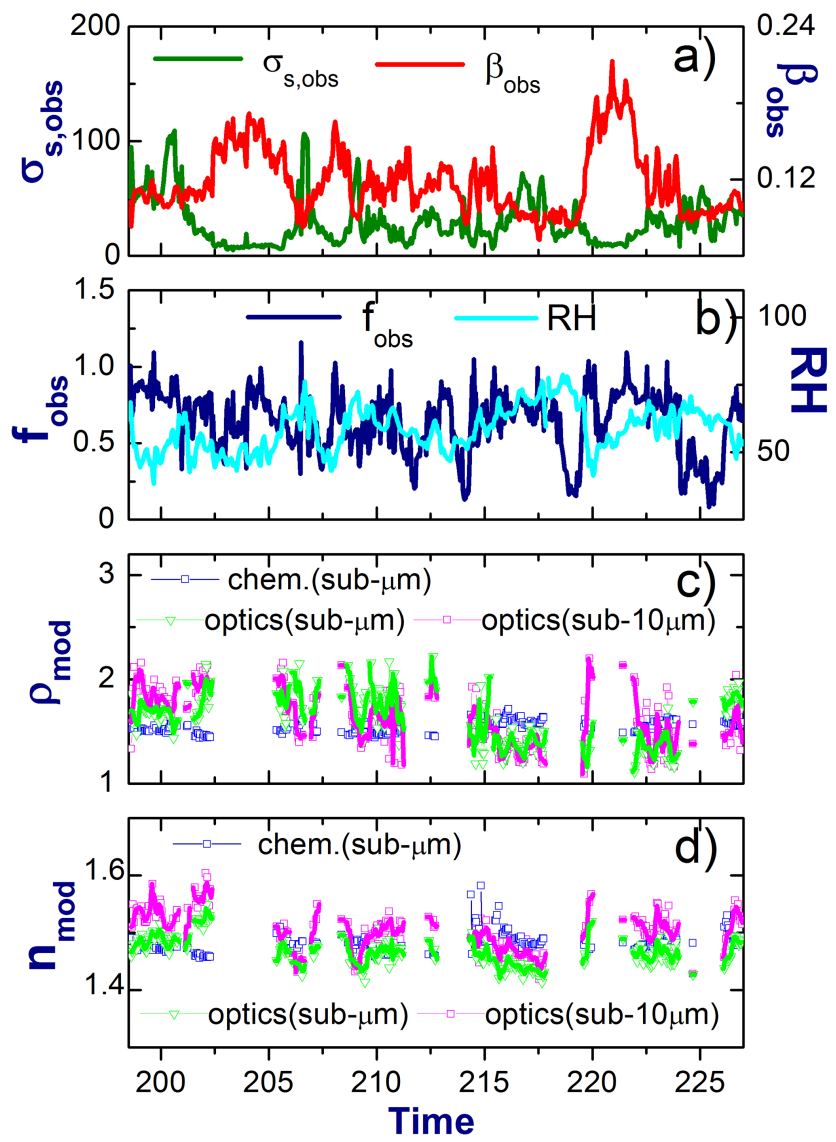

Figure 6. Time series of (a) light-scattering coefficient $\left(\sigma_{\mathrm{s}, \mathrm{obs}}\right)$ and hemispheric backscattering fraction $\left(\beta_{\mathrm{obs}}\right)$ measured for sub-10micron $\left(D_{\mathrm{p}}<10 \mu \mathrm{m}\right)$ particles by integrating nephelometer, (b) relative humidity $(\mathrm{RH})$ and the fine-mode fraction of light scattering $\left(f_{\text {obs }}\right)$, (c) the effective density calculated from the sub-micron $\left(D_{\mathrm{p}}<1 \mu \mathrm{m}\right)$ dry chemical composition ( $\rho_{\text {mod,chem }}$; blue squares) and the retrieved $\left(\rho_{\text {mod,opt }}\right)$ from optical properties measured for sub-micron (green triangles) and sub-10-micron (magenta squares) particles, and (d) the real refractive index calculated from the submicron dry chemical composition ( $n_{\text {mod,chem }}$; blue squares) and retrieved ( $\left.n_{\text {mod,opt }}\right)$ from optical properties measured for sub-micron (green triangles) and sub-10-micron (magenta squares) particles. (c, d) Solid lines (blue, green and magenta) represent the smoothed versions (boxcar averaging; 5 points) of the corresponding calculated and retrieved aerosol characteristics (blue, green, and magenta squares). Appendix B includes “zoom-in” versions of Fig. 6.

would require information on the imaginary refractive index (e.g., from independent measurements or/and related retrievals) and re-calculation of two-dimensional model optical properties required for step 2 of our retrieval (Sect. 2). In contrast to the retrieved aerosol characteristics, the chemically based counterparts $n_{\text {mod,chem }}$ and $\rho_{\text {mod,chem }}$ show weak temporal variations (Fig. 6c, d). Unlike the time series of the retrieved aerosol characteristics, the chemically based counterparts are temporally continuous, and in the interests of clarity 
in Fig. 6c and d, we include only parts of the chemically based time series which overlap with the retrieved variables.

\subsection{Basic statistics of observed and retrieved aerosol properties}

On average, the calculated characteristics based on chemical composition data and retrieved characteristics from the lightscattering data are comparable (Table 2a). For example, the mean values of the effective density are in a good agreement, with the sub-micron $\bar{\rho}_{\text {mod,chem }} \sim 1.54$ and the sub-10-micron $\bar{\rho}_{\text {mod,opt }} \sim 1.61$ values $($ Table $2 \mathrm{a})$. However, when considering time series of observed and retrieved variables, the difference between the two can be large for a given period of time (Fig. 6c, d). The evident time-dependent pattern of this difference can be attributed to two factors associated with the particle diameter (sub-micron versus sub-10micron) and humidity (dry versus wet). Recall that the chemically based aerosol characteristics $\left(n_{\text {mod,chem }}\right.$ and $\left.\rho_{\text {mod,chem }}\right)$ represent the dry measurements of sub-micron particles.

We first discuss the diameter-related factor for the dry conditions (Fig. 7, Table 2b). The mean value of the optically based sub-10-micron effective density $\left(\bar{\rho}_{\text {mod,opt }} \sim\right.$ $1.77)$ overestimates noticeably its chemically based counterpart $\left(\bar{\rho}_{\text {mod,chem }} \sim 1.52\right)$. The corresponding RMSE is about $35 \%$. Such overestimation could be associated with dust or sea-salt contributions to the coarse mode. The optically based sub-micron effective density ( $\left.\bar{\rho}_{\text {mod,opt }} \sim 1.68\right)$ is in better agreement with $\bar{\rho}_{\text {mod,chem }}$ (Fig. 7, Tables $2 \mathrm{~b}$ ), and the corresponding RMSE is about $28 \%$. This agreement is even more pronounced for the real refractive index: the mean sub-10micron $\left(\bar{n}_{\text {mod,opt }} \sim 1.53\right)$ and sub-micron $\left(\bar{n}_{\text {mod,opt }} \sim 1.49\right)$ values of the real refractive index overestimate slightly their chemically based counterpart $\left(\bar{n}_{\text {mod, chem }} \sim 1.48\right)$. The corresponding values of RMSE are about 6 and $3 \%$, respectively (Table $2 b$ ). The better agreement for the real refractive index compared to the effective density (Table 2b; Fig. 7) is consistent with the sensitivity study results. A related marine study (Quinn et al., 2004) has demonstrated that both the density and real refractive index of sampled aerosols are size dependent, and their dry values $(\mathrm{RH}=55 \pm 5 \%)$ are typically higher for large particles $(1.1-10 \mu \mathrm{m}$ range) than for sub-micron particles. The differences observed in the TCAP case study between the characteristics retrieved for dry suband sub-10-micron particles (Table $2 b$ ) are in line with these findings.

In contrast with the diameter factor, the humidity-related factor can modify both the magnitude and sign of the relative differences between mean values of the optically and chemically based aerosol characteristics (Tables $2 b, c)$, and both the shape and peak position of the corresponding probability distribution functions of the retrieval errors (Fig. 7). The observed RH sensitivity of the retrieved aerosol characteristics suggests that the $\mathrm{RH}$ corrections of the input parameters (Appendix A) only partially remove the corresponding $\mathrm{RH}$
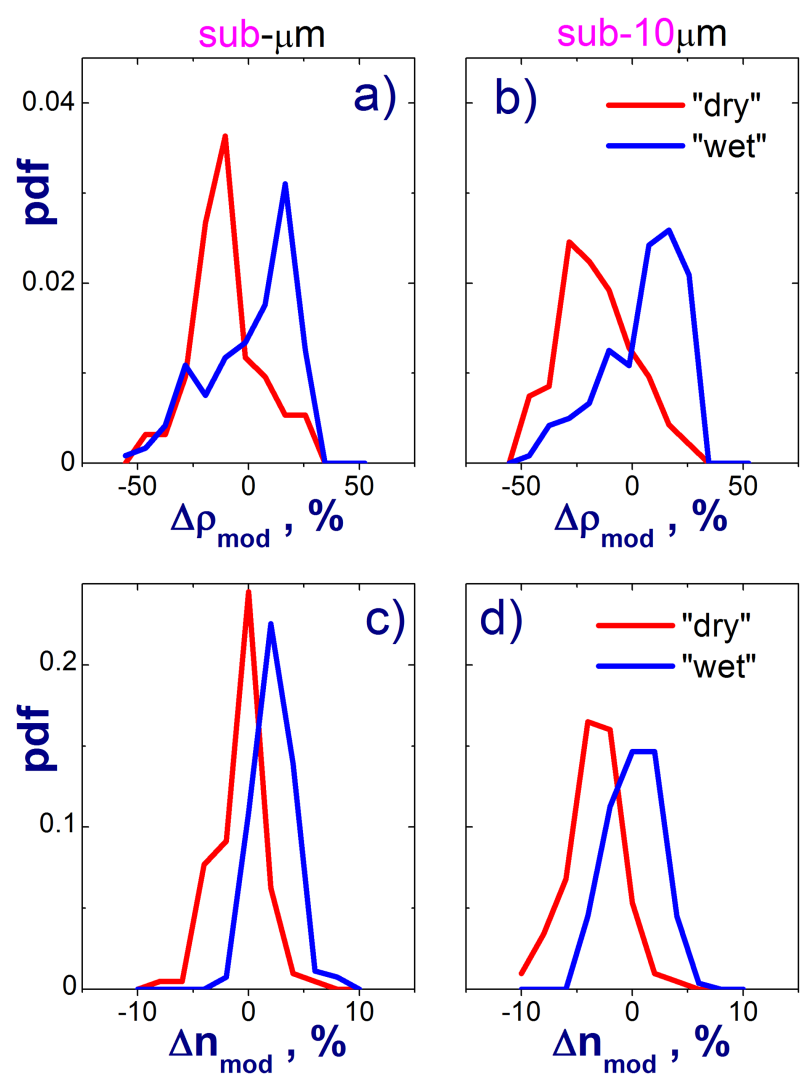

Figure 7. Probability distribution function (pdf) of the retrieval errors for the effective density $\left(\Delta \rho_{\text {mod }}\right)$ and the real refractive index $\left(\Delta n_{\text {mod }}\right)$ obtained for the sub-micron (left column) and sub10-micron (right column) particles. Red and blue colors define the retrieval errors obtained for the "dry" and "wet" conditions, respectively. Note that different scales are used for $\Delta \rho_{\text {mod }}$ (top row) and $\Delta n_{\text {mod }}$ (bottom row). Factors associated with particle diameter and humidity (see text for details) are the main sources of the observed differences between the pdfs (red versus blue colors).

dependence. For humid conditions, most of relative differences tend to have positive values; for dry conditions, the opposite is true (Fig. 7). The observed underestimation of retrieved characteristics under humid conditions is consistent with results from previous studies (e.g., Erlick et al., 2011) and can be explained as follows. The aerosol characteristics ( $n$ and $\rho$ ) have smaller values for the pure water than for other chemical components, and the fraction of aerosol water increases with an increase of the RH due to water uptake. This fraction depends on the hygroscopicity of aerosol and therefore on its chemical composition (e.g., Zieger et al., 2013 , and references therein). A comparison of results (Table 2 and Fig. 6; measured chemical data versus retrieved optical estimations) suggests that our retrieval can estimate the average values of the sub-micron aerosol characteristics quite accurately, yet the retrieval uncertainties can be large for the corresponding instantaneous values. 
Table 2a. Mean and standard deviation (SD) of the retrieved effective density $\left(\rho_{\text {mod }}\right)$ and real refractive index $\left(n_{\text {mod }}\right)$ obtained for all retrievals under wet and dry conditions (237 points). The RH is $58.4 \pm 8.1$ (mean $\pm \mathrm{SD}$ ). The chemically derived aerosol properties represent dry conditions only. The corresponding root mean squared error (RMSE) is defined as the root mean squared difference (\%) between the aerosol characteristics retrieved from the measured optical properties and their counterparts calculated from the chemical composition data. These basic statistics (mean, SD, and RMSE) represent both the sub- $\mu \mathrm{m}$ and sub- $10 \mu \mathrm{m}$ aerosol characteristics. As discussed in Barnard et al. (2010), uncertainties in the chemically derived density and refractive index are at least $5 \%$.

\begin{tabular}{llccc}
\hline Parameter & Model & Mean & SD & RMSE \\
\hline \multirow{2}{*}{$\rho_{\text {mod }}$} & Opt $($ sub-10 $\mu \mathrm{m})$ & 1.605 & 0.271 & 31.3 \\
& Opt $($ sub- $\mu \mathrm{m})$ & 1.602 & 0.252 & 28.9 \\
& Chem $($ sub- $\mu \mathrm{m})$ & 1.543 & 0.055 & - \\
\hline \multirow{2}{*}{$n_{\text {mod }}$} & Opt $($ sub-10 $\mu \mathrm{m})$ & 1.502 & 0.034 & 4.8 \\
& Opt $($ sub- $\mu \mathrm{m})$ & 1.467 & 0.026 & 3.8 \\
& Chem $(\mathrm{sub}-\mu \mathrm{m})$ & 1.481 & 0.017 & - \\
\hline
\end{tabular}

Table $2 \mathbf{b}$. The same as Table 2 a but for retrievals under dry conditions (104 points; $\mathrm{RH}=53.7 \pm 4.2$ ).

\begin{tabular}{llccc}
\hline Parameter & Model & Mean & SD & RMSE \\
\hline \multirow{2}{*}{$\rho_{\text {mod }}$} & Opt (sub-10 $\mu \mathrm{m})$ & 1.769 & 0.222 & 35.0 \\
& Opt (sub- $\mu \mathrm{m})$ & 1.677 & 0.208 & 27.8 \\
& Chem $($ sub- $\mu \mathrm{m})$ & 1.522 & 0.049 & - \\
\hline \multirow{2}{*}{$n_{\text {mod }}$} & Opt (sub-10 $\mu \mathrm{m})$ & 1.528 & 0.026 & 6.2 \\
& Opt (sub- $\mu \mathrm{m})$ & 1.487 & 0.022 & 3.3 \\
& Chem $($ sub- $\mu \mathrm{m})$ & 1.477 & 0.015 & - \\
\hline
\end{tabular}

Table 2c. The same as Table $2 \mathrm{a}$ but for retrievals under wet conditions (133 points; $\mathrm{RH}=65.7 \pm 3.9)$.

\begin{tabular}{llccc}
\hline Parameter & Model & Mean & SD & RMSE \\
\hline \multirow{2}{*}{$\rho_{\text {mod }}$} & Opt (sub-10 $\mu \mathrm{m})$ & 1.477 & 0.235 & 28.1 \\
& Opt (sub- $\mu \mathrm{m})$ & 1.544 & 0.269 & 29.7 \\
& Chem $($ sub- $\mu \mathrm{m})$ & 1.560 & 0.055 & - \\
\hline \multirow{2}{*}{$n_{\text {mod }}$} & Opt (sub-10 $\mu \mathrm{m})$ & 1.481 & 0.026 & 3.3 \\
& Opt (sub- $\mu \mathrm{m})$ & 1.451 & 0.016 & 4.2 \\
& Chem $($ sub- $\mu \mathrm{m})$ & 1.485 & 0.017 & - \\
\hline
\end{tabular}

Although the large $\left(1 \mu \mathrm{m}<D_{\mathrm{p}}<10 \mu \mathrm{m}\right)$ particles can be of significant importance in modeling aerosol radiative effects (e.g., Eck et al., 2010; Kassianov et al., 2012), in situ information of their physical and optical properties is often lacking. Therefore, there is a strong need to obtain the aerosol characteristics for large particles, and our approach can meet this need by retrieving characteristics for sub-micron and sub-10-micron particles separately.

\subsection{Retrieved size distributions}

The main objective of our approach is to retrieve in parallel the two aerosol characteristics $n$ and $\rho$, which provide closure for the two optical properties $\sigma_{\mathrm{s} \text {,obs }}$ and $\beta_{\text {obs. }}$. However, this optical closure could be obtained even for poorly merged SMPS and APS particle number size distributions. Before considering examples of the merged SMPS-APS distributions (Fig. 8), two points should be made. First, the upper diameter limit of the SMPS used in this study is $0.48 \mu \mathrm{m}$ (electrical mobility diameter), while the lower diameter limit of APS is $0.52 \mu \mathrm{m}$ (aerodynamic diameter) (Sect. 2). Second, the APS data near the lower limit are typically characterized by high uncertainties, and thus these data are avoided during the size distribution merging (e.g., Khlystov et al., 2004; Fig. 1). Similar to previous studies, we found that the APS data considered here frequently have unreliable counting for the first three bins (size range $0.52-0.58 \mu \mathrm{m}$ ). Therefore, a sufficient overlap (e.g., geometric size range about 0.38 $0.48 \mu \mathrm{m}$ ) between the measured SMPS and reliable APS size distributions does not exist. As a result, a direct application of the conventional alignment method for a given SMPS-APS data set is not possible.

To merge the SMPS and APS particle number size distributions, we apply a simple approach (Sect. 2) using the general framework that forms the basis of the conventional alignment method. We start with the replacement of the highly uncertain APS data for the three first bins by those obtained from a linear logarithmic extrapolation (log-log scale). This extrapolation involves reliable APS data from nearby bins (size range $0.58-0.67 \mu \mathrm{m}$ ) and provides "corrected" data for the first three bins (size range $0.52-0.58 \mu \mathrm{m}$ ) only. Then, the corrected APS particle number size distribution is shifted horizontally along the abscissa $\left(D_{\mathrm{p}}\right)$ according to an assumed value of the effective density - a procedure similar to the alignment method (Fig. 1a). If during such horizontal shifting a fraction of APS spectra overlaps with fixed SMPS particle number size distribution, this "overlapping" APS fraction is removed from further consideration. Thus, the merged SMPS-APS particle number size distribution (for a given effective density) includes the fixed SMPS spectra and "nonoverlapping" fraction of APS data. The merging criterion is a value of the effective density that provides closure for two optical properties $\left(\sigma_{\mathrm{s}, \mathrm{obs}}\right.$ and $\left.\beta_{\mathrm{obs}}\right)$. We emphasize that our approach and the conventional alignment method have a very similar shifting procedure to APS spectra but distinct criteria for obtaining the combined SMPS-APS particle number size distribution: the merging criterion based on optical closure (our approach) and alignment criterion based on size distribution fitting in the overlap size range (alignment method).

To make sure that the obtained particle number and volume size distributions are aligned reasonably well, we consider them for both dry and humid conditions (Fig. 8). For dry conditions, the large particles barely contribute to the combined particle volume size distributions, and hence these 

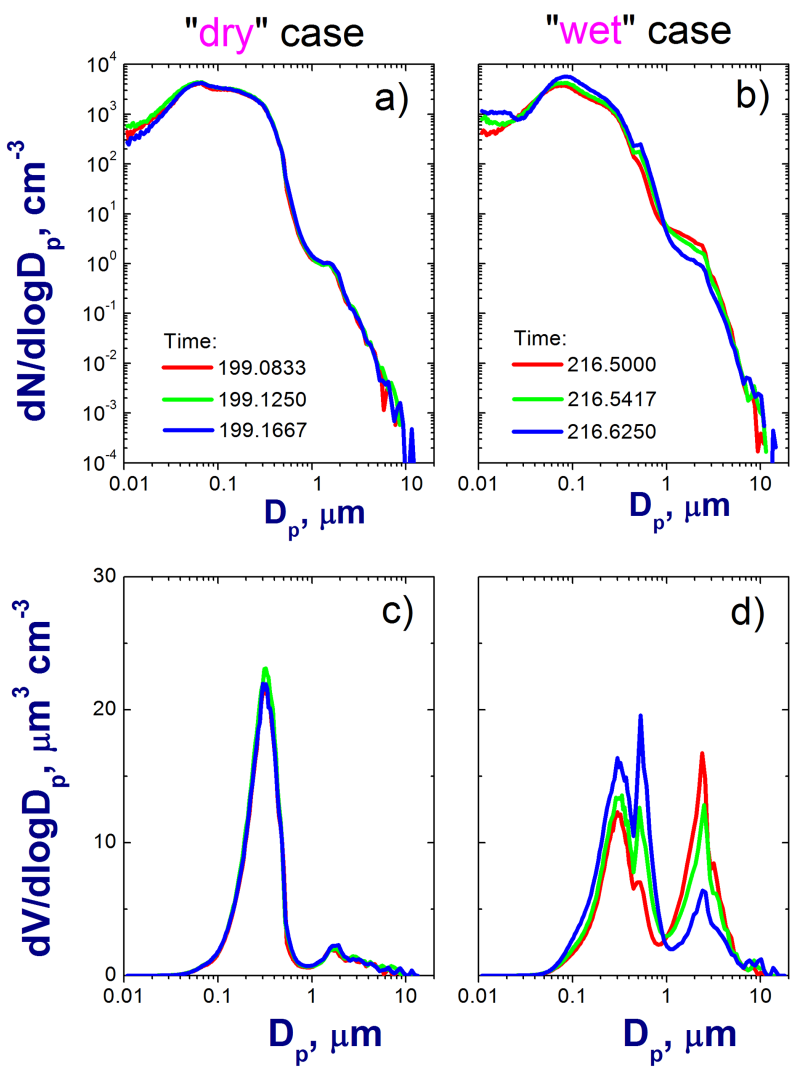

Figure 8. Particle number (top row) and volume (bottom row) size distributions obtained from the retrieved effective density $\left(\rho_{\mathrm{mod}}\right)$ and the measured SMPS and APS spectra. Red, green, and blue colors are used for different time steps within specified sub-periods (Appendix B). These sub-periods represent cases with similar optical properties but very different values of the instrument RH. For the first sub-period (dry case; left column), the RH is relatively small (RH $\sim 45 \%$ ). For the second sub-period (wet case; right column), the $\mathrm{RH}$ is relatively high $(\mathrm{RH} \sim 70 \%)$.

distributions have weakly defined coarse modes (Fig. 8a, c). For the particle volume size distributions that occur under wet conditions, contributions of the small $\left(D_{\mathrm{p}}<0.5 \mu \mathrm{m}\right)$, moderate $\left(0.5 \mu \mathrm{m}<D_{\mathrm{p}} \leq 1.0 \mu \mathrm{m}\right)$, and sub-10-micron particles to the volume distribution are comparable, and hence these volume distributions may have multi-modal structure with well-defined fine, intermediate, and coarse modes with peaks near $0.30,0.55$, and $2.5 \mu \mathrm{m}$, respectively (Fig. 8d). Since the size of particles increases substantially during water uptake, the observed multi-modal structure of the wet distributions can be associated with measured particle composition/size and the RH-related particle growth. Most importantly, however, visual inspection indicates that there are no major alignment problems in the overlap region, and therefore our retrieval shows the capability to align smoothly the measured SMPS and APS spectra. In this regard, the suggested retrieval shares this important capability with established alignment methods (e.g., Hand and Kreidenweis, 2002; Khlystov et al., 2004).

\section{Summary}

We introduce a novel approach that retrieves simultaneously two critical aerosol characteristics, the effective density and real refractive index of weakly absorbing aerosol (singlescattering albedo >0.95) at arbitrary RH. We illustrate our approach using the scattering coefficient and the hemispheric backscatter fraction measured by an integrating nephelometer, and size spectra measured by a SMPS and APS. This simultaneous retrieval is the novel element of our approach, which combines advantages of the conventional optical closure and alignment methods. Since the two observational constraints (the scattering coefficient and the hemispheric backscatter fraction) have a strong link to the aerosol optical depth and asymmetry parameter, which are important in the context of the Earth's radiation budget, the retrieved aerosol characteristics are climate-relevant as well.

We demonstrate the performance of our approach using both a sensitivity study with synthetically generated inputs with random noise and a case study with real measurements, which cover a wide range of coastal summertime conditions observed during the TCAP field campaign (http://campaign. arm.gov/tcap/). These measurements include events with a wide range of aerosol loading and relative humidity. The sensitivity study shows that (1) the uncertainties of the aerosol retrieval are almost linearly proportional to the measurement errors and that (2) the retrievals of the real refractive index, in comparison with the effective density, are more robust. The case study using real data supports these findings. For the real refractive index, the retrieved dry sub-micron value $(1.49 \pm 0.02)$ from the light-scattering measurements is in very good agreement (RMSE is about $3 \%$ ) with that obtained from the chemical composition measurements. The corresponding agreement is reasonable (RMSE is about $28 \%$ ) for the retrieved effective density $(1.68 \pm 0.21)$. Moreover, the retrieved effective density and real refractive index exhibit a tendency to decrease gradually with increase of the relative humidity, and the observed tendency is consistent with the present knowledge of the hydroscopic nature of aerosols.

The majority of existing methods, such as frequently used techniques based on chemical composition measurements, offer essential information on the aerosol characteristics of sub-micron particles. However, such information for the large particles $\left(1 \mu \mathrm{m}<D_{\mathrm{p}}<10 \mu \mathrm{m}\right)$ from many current field instruments is mostly lacking. Our retrieval overcomes this limitation using light-scattering measurements of both submicron and sub-10-micron aerosol optical parameters, which in turns permits discrimination between retrieved aerosol characteristics of small and large particles. This size-resolved information, as a new aspect of future studies, will be vital for better understanding the sources, formation, and fate of aerosol particles, and for evaluating and improving regional and large-scale climate models. 


\section{Appendix A: Truncation error correction}

This appendix includes details related to the calculations of the aerosol optical properties, namely the scattering coefficient $\left(\sigma_{\mathrm{s}}\right)$ and hemispheric backscattering coefficient $\left(\sigma_{\mathrm{bs}}\right)$. Recall that the backscatter fraction $(\beta)$ is defined as the ratio of the hemispheric backscattering and total scattering coefficients. The relationship between these coefficients and aerosol microphysical properties can be described as follows (e.g., Pilninis and Li, 1998):

$$
\begin{aligned}
& \sigma_{\mathrm{s}}(\rho, n)=\sum_{k=1}^{N} \frac{3 M_{k}}{2 D_{k}^{3} \rho_{k}} \int_{\theta_{1}}^{\theta_{2}} f\left(n_{k}, D_{k}, \theta\right) Z_{\mathrm{s}}(\theta) \mathrm{d} \theta \\
& \sigma_{\mathrm{bs}}(\rho, n)=\sum_{k=1}^{N} \frac{3 M_{k}}{2 D_{k}^{3} \rho_{k}} \int_{\pi / 2}^{\theta_{2}} f\left(n_{k}, D_{k}, \theta\right) Z_{\mathrm{bs}}(\theta) \mathrm{d} \theta
\end{aligned}
$$

where $M_{k}, D_{k}$, and $\rho_{k}$ are the aerosol concentration, particle diameter, and density for a given size bin $(k)$, respectively. The scattering function $(f)$ is proportional to the phase function and depends on the scattering angle $(\theta)$, wavelength, particle number size distribution and complex index of refraction. Here we specify implicitly this dependence on particle diameter $(D)$ and real refractive index $(n)$. The lower $\left(\theta_{1}\right)$ and upper $\left(\theta_{2}\right)$ limits define the angular range of nephelometer measurements, while $Z_{\mathrm{s}}(\theta)$ and $Z_{\mathrm{bs}}(\theta)$ represent the angular sensitivity functions for the total scatter and hemispheric backscatter, respectively. For an ideal case, the integration in Eqs. (A1) and (A2) is performed over the full angular range $\left(\theta_{1}=0\right.$ and $\left.\theta_{2}=\pi\right)$ for a Lambertian light source $\left(Z_{\mathrm{s}}(\theta)=Z_{\mathrm{bs}}(\theta)=\sin (\theta)\right)$. For a real case, the integration is performed over the incomplete angular range $\left(\theta_{1} \approx 7^{\circ}\right.$ and $\theta_{2} \approx 170^{\circ}$ ) for a non-Lambertian light source (functions $Z_{\mathrm{s}}(\theta)$ and $Z_{\mathrm{bs}}(\theta)$ are non-sinusoidal) (e.g., Anderson et al., 1996).

The inclusion of a non-Lambertian light source and incomplete angular integration are well-known non-idealities of the TSI 3563 Integrating Nephelometer. To reduce systematic errors associated with these non-idealities, several conventional corrections have been suggested for both slightly absorbing (e.g., Anderson and Ogren; 1998) and highly absorbing (e.g., Bond et al., 2009) particles. In particular, Anderson and Ogren (1998) have demonstrated through detailed Mie calculations and typical bimodal size distributions that systematic truncation errors are quite small $(<10 \%)$ and substantial (up to $50 \%$ ) for sub- $\mu \mathrm{m}$ and super- $\mu \mathrm{m}$ particles, respectively. Also, Anderson and Ogren (1998) have suggested a conventional truncation error correction, which is a common premise in many studies based on integrated nephelometry (e.g., Anderson et al., 1999; Titos et al., 2014). Recently, Ma et al. (2014) confirmed that this conventional correction works reasonably well for cases where the aerosol volume concentration is dominated by sub-micron particles. Since sub-micron particles have dominated the particle lightscattering coefficient for the majority of events considered here (e.g., Fig. 6b), it is expected that this conventional correction is sufficient to address issues associated with the truncation error. For our study, we use publically available and corrected data for TSI 3563 Integrating Nephelometer obtained from the ARM archive. The corrections that have been applied include the conventional truncation error correction according to Anderson and Ogren (1998), and they form the basis of the standard initial data processing and quality control procedure. The latter is implemented in the ARM data ingest protocol for the Aerosol Observing System (AOS) with the TSI 3563 Integrating Nephelometer.

The calculations of optical properties of sub-micron and sub-10-micron particles $\left(\sigma_{\mathrm{s}}\right.$ and $\beta$ ) are based on Mie codes developed by Barber and Hill (1990). These calculations are performed for the ideal case (weakly absorbing aerosol) outlined above. We assume that values of the density and real refractive index are bin-independent within the sub-micron or sub-10-micron diameter range, and thus they define the corresponding effective values for the sub-micron and sub10-micron particles. To resolve accurately the angular distribution of the scattered light, variable angular resolution is applied: from $0.05^{\circ}$ (near-forward direction) to $1^{\circ}$ (nearbackward direction). Selection of the angular resolution is driven mostly by a trade-off between the speed and accuracy of Mie calculations.

\section{Appendix B: Relative humidity corrections}

\section{Coarse-mode size distribution (PNNL-APS) adjustment to relative humidity of $\mathbf{4 0} \%$}

The relative humidity of the sample flow changed due to temperature changes as the sample propagated from outside (ambient conditions) into the APS, which was installed inside a climate-controlled trailer. The APS was placed as close as practical to the main inlet stack of the trailer; no control on the sample line relative humidity was exercised. The relative humidity of the APS sample line is not normally measured; so, strictly speaking, particle number size distribution measurements were performed under unknown relative humidity.

We have estimated the relative humidity inside the APS sample line using the temperature inside the APS (reported in parameter "Box Temperature") and the absolute humidity of ambient air calculated from the ambient temperature and RH (measured by the Mobile Aerosol Observing System (MAOS)). The APS measured particle number size distributions were adjusted for hygroscopicity following a generally accepted approach (e.g., Swietlicki et al., 2000): the hygroscopic diameter growth factors $G(\mathrm{RH})=\frac{D_{\mathrm{RH}}}{D_{\mathrm{dry}}}$ are parameterized as

$$
G(\mathrm{RH})=\left(1-\frac{\mathrm{RH}}{100}\right)^{-\gamma} .
$$

A value of 0.233 for the parameter $\gamma$ was adopted from Swietlicki et al. (2000), recommended for clean marine air mass 
with RH within $0<\mathrm{RH}<95 \%$ and wind speed below $8 \mathrm{~m} \mathrm{~s}^{-1}$ (for which local sea-salt aerosol production is small); relative humidity of $40 \%$ was assumed for dry size. In particular, the World Meteorological Organization recommends RH levels of $40 \%$ or below (WMO/GAW, 2003). Note that the selected value $(\gamma=0.233)$ was obtained for a particle diameter of 166 $\mathrm{nm}$; the data on hygroscopic growth of super-micron aerosol is virtually nonexistent.

\section{Scattering coefficient (NOAA AOS dry Nephelometer) adjustment to relative humidity of $40 \%$}

Due to technical difficulties, the relative humidity inside the AOS dry nephelometer was not kept at $40 \%$ or below (as recommended by the WMO). We have adjusted the scattering coefficients to $\mathrm{RH}_{\text {dry }}=40 \%$ using a generally accepted approach (e.g., Gasso et al., 2000; Crahan et al., 2004): the dependence of aerosol scattering on RH was parameterized though aerosol hygroscopic exponent $\alpha$ :

$\sigma_{\mathrm{sp}}(\mathrm{RH})=\sigma_{\mathrm{sp}}\left(\mathrm{RH}_{\mathrm{dry}}\right)\left(1-\frac{\mathrm{RH}}{100}\right)^{-\alpha}$.

The relative humidity inside the nephelometer was estimated using the temperature inside the nephelometer (reported in parameter Box Temperature) and the absolute humidity of ambient air calculated from the ambient temperature and $\mathrm{RH}$ (measured by the MAOS). Gasso et al. (2000) reported $\alpha$ values of 0.57 for polluted marine and 0.73 for clean marine aerosol; Crahan et al. (2004) reported $\alpha$ values between 0.23 and 0.48 for marine air masses, with an average for coastal air of 0.45 . Here we use value of 0.5 for parameter $\alpha$.

\section{Appendix C: Examples of dry and wet sub-periods}

This section shows time series of the measured and retrieved aerosol parameters for the dry (Fig. C1) and wet (Fig. C2) conditions. The selected dry and wet sub-periods have similar mean values of the scattering coefficient $\left(\bar{\sigma}_{\mathrm{s} \text {,dry }} \sim 60 \mathrm{Mm}^{-1}\right.$ versus $\left.\bar{\sigma}_{\mathrm{s} \text {, wet }} \sim 50 \mathrm{Mm}^{-1}\right)$, hemispherical backscatter fraction $\left(\bar{\beta}_{\text {dry }} \sim 0.11\right.$ versus $\left.\bar{\beta}_{\text {wet }} \sim 0.08\right)$, and fine-mode fraction of light scattering $\left(\bar{f}_{\text {dry }} \sim 0.9\right.$ versus $\left.\bar{f}_{\text {wet }} \sim 0.8\right)$. In contrast, these sub-periods have very different mean values of the $\mathrm{RH}$ within the nephelometer $\left(\mathrm{RH}_{\text {dry }} \sim\right.$ $45 \%$ versus $\mathrm{RH}_{\text {wet }} \sim 70 \%$ ).

These plots (Figs. C1 and C2) illustrate two important points: (1) the retrieved optically based aerosol characteristics ( $\rho_{\text {mod,opt }}$ and $\left.n_{\text {mod,opt }}\right)$ overestimate and underestimate their chemically based counterparts ( $\rho_{\text {mod,chem }}$ and $n_{\text {mod,chem }}$ ) for the dry (Fig. C1c, d) and wet (Fig. C2c, d) conditions, respectively, and (2) the obtained overestimation is more pronounced for the sub-10-micron optically based characteristics compared to the sub-micron characteristics.
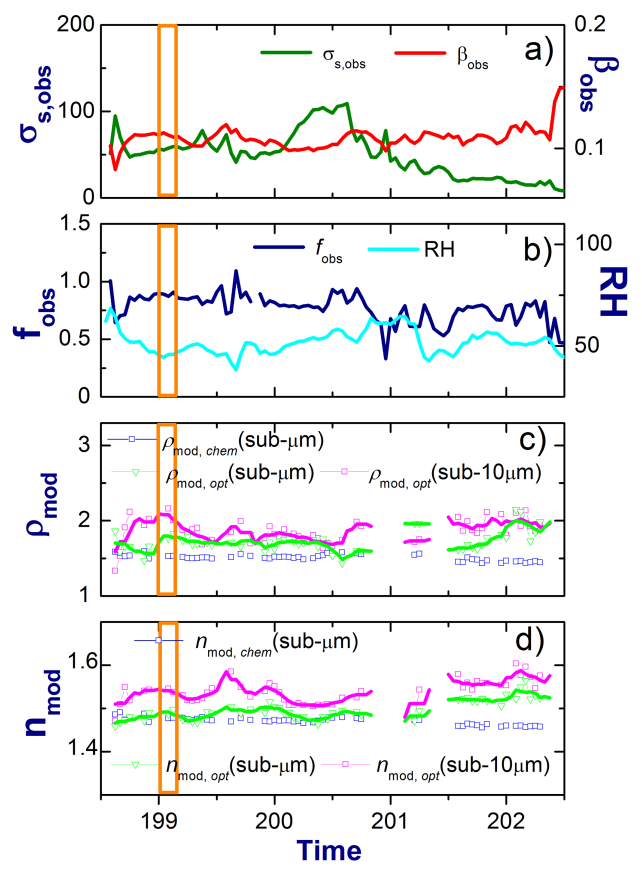

Figure C1. The same as Fig. 6 but for selected dry period (52 points, $\mathrm{RH}=51.9 \pm 5.8$ ). The vertical orange bar represents a sub-period where the optical properties of dry particles (Fig. C1) are comparable with those obtained for their wet counterparts (Fig. C2), but values of the RH are very different.
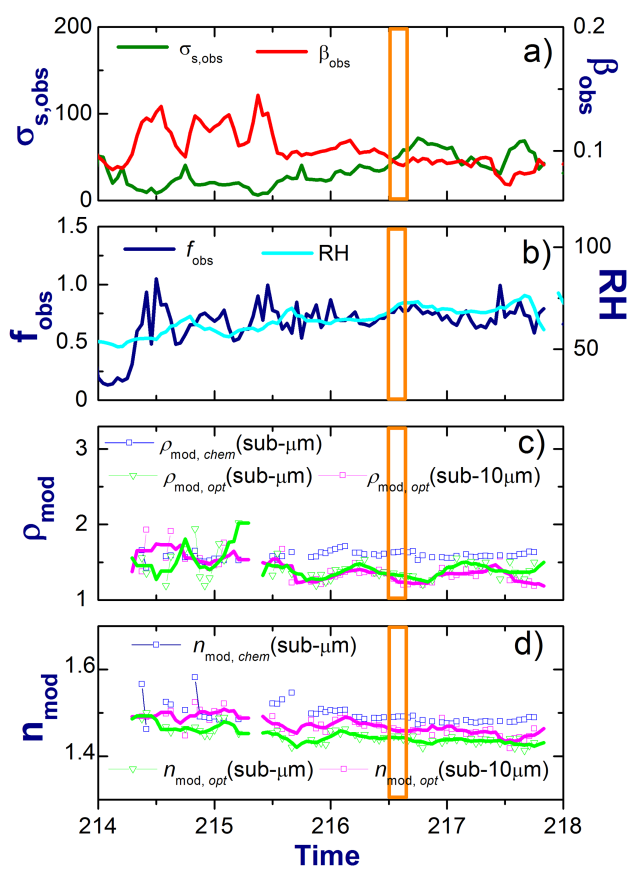

Figure C2. The same as Fig. 6 but for selected wet period (56 points, $\mathrm{RH}=64.2 \pm 6.3$ ). The vertical orange bar represents a subperiod where the optical properties of wet particles (Fig. C2) are comparable with those obtained their dry counterparts (Fig. C1), but values of the RH are very different. 
Acknowledgements. This work has been supported by the Office of Biological and Environmental Research (OBER) of the US Department of Energy (DOE) as part of the Atmospheric Radiation Measurement (ARM) and Atmospheric System Research (ASR) programs. The Pacific Northwest National Laboratory (PNNL) is operated by Battelle for the DOE under contract DE-A06-76RLO 1830. We are grateful to Prof. Wiedensohler and two anonymous reviewers for their thoughtful comments that helped improve our paper.

Edited by: A. Wiedensohler

\section{References}

Anderson, T. L., Covert, D. S., Wheeler, J. D., Harris, J. M., Perry, K. D., Trost, B. E., Jaffe, D. J., and Ogren, J. A.: Aerosol backscatter fraction and single scattering albedo: Measured values and uncertainties at a coastal station in the Pacific Northwest, J. Geophys. Res., 104, 26793-26807, doi:10.1029/1999JD900172, 1999.

Anderson, T. L. and Ogren, J. A.: Determining aerosol radiative properties using the TSI 3563 integrating nephelometer, Aerosol Sci. Technol., 29, 57-69, 1998.

Anderson, T. L., Covert, D. S., Marshall , S. F., Laucks, M. L., Charlson, R. J., Waggoner, A. P., Ogren, J. A., Caldow, R., Holm, R. L., Quant, F. R., Sem, G. J., Wiedensohler, A., Ahlquist, N. A., and Bates, T. S.: Performance characteristics of a high-sensitivity, three-wavelength, total scatter/backscatter nephelometer, J. Atmos. Oceanic Technol., 13, 967-986, doi:10.1175/1520-0426(1996)013<0967:PCOAHS>2.0.CO;2, 1996.

Andrews, E., Sheridan, P. J., Fiebig, M., McComiskey, A., Ogren, J. A., Arnott, P., Covert, D., Elleman, R., Gasparini, R., Collins, D., Jonsson, H., Schmid, B., and Wang, J.: Comparison of methods for deriving aerosol asymmetry parameter. J. Geophys. Res.Atmos., 111, D05S04, doi:10.1029/2004JD005734, 2006.

Barber, P. W. and Hill, S. C.: Light scattering by particles: Computational methods, World Scientific Publishing, Singapore, 1990.

Barnard, J. C., Volkamer, R., and Kassianov, E. I.: Estimation of the mass absorption cross section of the organic carbon component of aerosols in the Mexico City Metropolitan Area, Atmos. Chem. Phys., 8, 6665-6679, doi:10.5194/acp-8-6665-2008, 2008.

Barnard, J. C., Fast, J. D., Paredes-Miranda, G., Arnott, W. P., and Laskin, A.: Technical Note: Evaluation of the WRF-Chem "Aerosol Chemical to Aerosol Optical Properties" Module using data from the MILAGRO campaign, Atmos. Chem. Phys., 10, 7325-7340, doi:10.5194/acp-10-7325-2010, 2010.

Baron, P. A. and Willeke, K.: Aerosol Measurement: Principles, Techniques and Applications, 2nd Edition, Wiley-Interscience, New York, 2001.

Berg, L. K., Fast, J. D., Barnard, J. C., Burton, S. P., Cairns, B., Chand, D., Comstock, J. M., Dunagan, S., Ferrare, R. A., Flynn, C. J., Hair, J. W., Hostetler, C. A., Hubbe, J., Jefferson, A., Johnson, R., Kassianov, E. I., Kluzek, C. D., Kollias, P., Lamer, K., Lantz, K., Mei, F., Miller, M. A., Michalsky, J., Ortega, I., Pekour, M., Rogers, R. R., Russell, P. B., Redemann, J., Sedlacek III, A. J., Segal-Rosenheimer, M., Schmid, B., Shilling, J. E., Shinozuka, Y., Springston, S. R., Tomlinson, J. M., Tyrrell, M., Wilson, J. M., Volkamer, R., Zelenyuk, A., and Berkowitz,
C. M.: The Two-Column Aerosol Project: Phase I overview and impact of elevated aerosol layers on aerosol optical depth, J. Geophys. Res.-Atmos., under review, 2014.

Bond, T. C, Covert, D. S., and Müller, T.: Truncation and angularscattering corrections for absorbing aerosol in the TSI 3563 Nephelometer, Aerosol Sci. Tech., 43, 866-871, 2009.

Chamaillard, K., Kleefeld, C., Jennings, S. G., Ceburnis, D., and O'Dowd, C. D.: Light scattering properties of sea-salt aerosol particles inferred from modeling studies and ground-based measurements, J. Quant. Spectrosc. Radiat. Transfer, 101, 498-511, doi:10.1016/j.jqsrt.2006.02.062, 2006.

Chartier, R. T. and Greenslade, M. E.: Initial investigation of the wavelength dependence of optical properties measured with a new multi-pass Aerosol Extinction Differential Optical Absorption Spectrometer (AE-DOAS), Atmos. Meas. Tech., 5, 709-721, doi:10.5194/amt-5- 709-2012, 2012.

Crahan, K. K., Hegg, D. A., Covert, D. S., Jonsson, H., Reid, J. S., Khelif, D., and Brooks, B. J.: Speciation of organic aerosols in the Tropical mid-Pacific and their relationship to light scattering, J. Atmos. Sci., 61, 2544-2558, 2004.

Cross, E. S., Slowik, J. G., Davidovits, P., Allan, J. D., Worsnop, D. R., Jayne, J. T., Lewis, D. K., Canagaratna, M., and Onasch, T. B.: Laboratory and ambient particle density determinations using light scattering in conjunction with aerosol mass spectrometry, Aerosol Sci. Technol., 41, 343-359, 2007.

DeCarlo, P. F., Slowik, J. G., Worsnop, D. R., Davidovits, P., and Jimenez, J. L.: Particle morphology and density characterization by combined mobility and aerodynamic diameter measurements. Part 1: Theory, Aerosol Sci. Technol., 38, 1185-1205, doi:10.1080/027868290903907, 2004.

Eck, T. F., Holben, B. N., Sinyuk, A., Pinker, R. T., Goloub, P., Chen, H., Chatenet, B., Li, Z., Singh, R. P., Tripathi, S. N., Reid, J. S., Giles, D. M., Dubovik, O., O’Neill, N. T., Smirnov, A., Wang, P., and Xia, X.: Climatological aspects of the optical properties of fine/coarse mode aerosol mixtures, J. Geophys. Res.Atmos., 115, D19205, doi:10.1029/2010JD014002, 2010.

Erlick, C., Abbatt, J. P. D., and Rudich, Y.: How different calculations of the refractive index affect estimates of the radiative forcing efficiency of ammonium sulfate aerosols, J. Atmos. Sci., 68, 1845-1852, doi:10.1175/2011JAS3721.1, 2011.

Fujitani, Y., Murao, N., Ohta, S., Endoh, T., and Yamagata, S.: Optical and chemical properties of marine aerosols over the central equatorial Pacific Ocean during the 2003 R/V Mirai cruise, J. Geophys. Res.-Atmos., 112, D11213, doi:10.1029/2006JD008354, 2007.

Gasso, S., Hegg, D. A., Covert, D. S., Collins, D., Noone, K. J., Ostrom, E., Schmid, B., Russell, P. B., Livingston, J. M., Durkee, P. A., and Jonsson, H.: Influence of humidity on the aerosol scattering coefficient and its effect on the upwelling radiance during ACE-2, Tellus B, 52, 546-567, 2000.

Ghan, S. J. and Schwartz, S. E.: Aerosol Properties and processes: A Path from field and laboratory measurements to Global Climate Models, B. Am. Meteor. Soc., 88, 1059-1083, doi:10.1175/BAMS-88-7-1059, 2007.

Guerrero-Rascado, J. L., Andrey, J., Sicard, M., Molero, F., Comerón, A., Pujadas, M., Rocadenbosch, F., Pedrós, R., SerranoVargas, O., Gil, M., Olmo, F. J., Lyamani, H., Navas-Guzmán, F., and Alados-Arboledas, L.: Aerosol closure study by lidar, Sun photometry, and airborne optical counters during DAMOCLES 
field campaign at El Arenosillo sounding station, Spain, J. Geophys. Res.-Atmos., 116, D02209, doi:10.1029/2010JD014510, 2011.

Hand, J. L. and Kreidenweis, S. M.: A new method for retrieving particle refractive index and effective density from aerosol size distribution data, Aerosol Sci. Technol., 36, 1012-1026, 2002.

Kassianov, E., Barnard, J., Pekour, M., Berg, L. K., Michalsky, J., Lantz, K., and Hodges, G.: Do diurnal aerosol changes affect daily average radiative forcing?, Geophys. Res. Lett., 40, 32653269, doi:10.1002/grl.50567, 2013.

Kassianov, E., Pekour, M., and Barnard, J.: Aerosols in central California: Unexpectedly large contribution of coarse mode to aerosol radiative forcing, Geophys. Res. Lett., 39, L20806, doi:10.1029/2012GL053469, 2012.

Khlystov, A., Stanier, C., and Pandis, S. N.: An algorithm for combining electrical mobility and aerodynamic size distributions data when measuring ambient aerosol, Aerosol Sci. Technol., 38, 229-238, 2004.

Liu, Y. and Daum, P. H.: The effect of refractive index on size distributions and light scattering coefficients derived from optical particle counters, J. Aerosol Sci., 8, 945-957, 2000.

Ma, N., Birmili, W., Müller, T., Tuch, T., Cheng, Y. F., Xu, W. Y., Zhao, C. S., and Wiedensohler, A.: Tropospheric aerosol scattering and absorption over central Europe: a closure study for the dry particle state, Atmos. Chem. Phys., 14, 6241-6259, doi:10.5194/acp-14-6241-2014, 2014.

Mack, L. A., Levin, E. J. T., Kreidenweis, S. M., Obrist, D., Moosmüller, H., Lewis, K. A., Arnott, W. P., McMeeking, G. R., Sullivan, A. P., Wold, C. E., Hao, W.-M., Collett Jr., J. L., and Malm, W.C.: Optical closure experiments for biomass smoke aerosols, Atmos. Chem. Phys., 10, 9017-9026, doi:10.5194/acp-10-90172010, 2010.

Matsui, H., Koike, M., Kondo, Y., Moteki, N., Fast, J. D., and Zaveri, R. A.: Development and validation of a black carbon mixing state resolved three-dimensional model: Aging processes and radiative impact, J. Geophys. Res. Atmos., 118, 2304-2326, doi:10.1029/2012JD018446, 2013.

McComiskey, A., Schwartz, S. E., Schmid, B., Guan, H., Lewis, E. R., Ricchiazzi, P., and Ogren, J. A.: Direct aerosol forcing: Calculation from observables and sensitivities to inputs, J. Geophys. Res.-Atmos., 113, D09202, doi:10.1029/2007JD009170, 2008.

Pilinis, C. and Li, X.: Particle shape and internal inhomogeneity effects on the optical properties of tropospheric aerosols of relevance to climate forcing, J. Geophys. Res., 103, 3789-3800, 1998.

Quinn P. K., Coffman, D. J., Bates, T. S., Welton, E. J., Covert, D. S., Miller, T. L., Johnson, J. E., Maria, S., Russell, L., Arimoto, R., Carrico, C. M., Rood, M. J., and Anderson, J.: Aerosol optical properties measured on board the Ronald H. Brown during ACE-Asia as a function of aerosol chemical composition and source region, J. Geophys. Res.-Atmos., 109, D19S01, doi:10.1029/2003JD004010, 2004.
Raut, J.-C. and Chazette, P.: Retrieval of aerosol complex refractive index from a synergy between lidar, sunphotometer and in situ measurements during LISAIR experiment, Atmos. Chem. Phys., 7, 2797-2815, doi:10.5194/acp-7-2797-2007, 2007.

Swietlicki, E., Zhou, J., Covert, D., Hämeri, K., Busch, B., Väkeva, M., Dusek, U., Berg, O., Wiedensohler, A., Aalto, P., Mäkelä, J., Martinsson, B., Papaspiropoulos, G., Mentes, B., Frank, G., and Stratmann, F.: Hygroscopic properties of aerosol particles in the north-eastern Atlantic during ACE-2, Tellus B, 52, 201-227, 2000 .

Titos, G., Jefferson, A., Sheridan, P. J., Andrews, E., Lyamani, H., Alados-Arboledas, L., and Ogren, J. A.: Aerosol light-scattering enhancement due to water uptake during the TCAP campaign, Atmos. Chem. Phys., 14, 7031-7043, doi:10.5194/acp-14-70312014, 2014.

Wex, H., Neusüß, C., Wendisch, M., Stratmann, F., Koziar, C., Keil, A., Wiedensohler, A., and Ebert, M.: Particle scattering, backscattering, and absorption coefficients: An in situ closure and sensitivity study, J. Geophys. Res.-Atmos., 107, 8122, doi:10.1029/2000JD000234, 2002.

Wiedensohler, A., Birmili, W., Nowak, A., Sonntag, A., Weinhold, K., Merkel, M., Wehner, B., Tuch, T., Pfeifer, S., Fiebig, M., Fjäraa, A. M., Asmi, E., Sellegri, K., Depuy, R., Venzac, H., Villani, P., Laj, P., Aalto, P., Ogren, J. A., Swietlicki, E., Williams, P., Roldin, P., Quincey, P., Hüglin, C., FierzSchmidhauser, R., Gysel, M., Weingartner, E., Riccobono, F., Santos, S., Grüning, C., Faloon, K., Beddows, D., Harrison, R., Monahan, C., Jennings, S. G., O’Dowd, C. D., Marinoni, A., Horn, H.-G., Keck, L., Jiang, J., Scheckman, J., McMurry, P. H., Deng, Z., Zhao, C. S., Moerman, M., Henzing, B., de Leeuw, G., Löschau, G., and Bastian, S.: Mobility particle size spectrometers: harmonization of technical standards and data structure to facilitate high quality long-term observations of atmospheric particle number size distributions, Atmos. Meas. Tech., 5, 657-685, doi:10.5194/amt-5-657-2012, 2012.

WMO/GAW: Aerosol measurement procedures guidelines and recommendations, GAWRep. 153, World Meteorol. Organ., Geneva, Switzerland, available at: http://www.wmo.int/pages/ prog/gcos/documents/gruanmanuals/GAW/gaw153.pdf (last access: May 2014), 2003.

Zieger P., Fierz-Schmidhauser, R., Weingartner, E., and Baltensperger, U.: Effects of relative humidity on aerosol light scattering: results from different European sites, Atmos. Chem. Phys., 13, 10609-10631, doi:10.5194/acp-13-10609-2013, 2013. 